\title{
BIO PSIKO SEKSUAL DAN SOSIAL IBU POSTPARTUM DENGAN RIWAYAT PERSALINAN RUPTURE PERINEUM
}

\author{
"Yolanda Montessori, Sri Handayani, Anjarwati \\ Kebidanan, Universitas ‘Aisyiyah Yogyakarta, 'email: montessoriyolanda@gmail.com
}

\section{INFO ARTIKEL}

Riwayat Artikel:

Diterima: 17-01-2020

Disetujui: 18-03-2020

\section{Kata Kunci:}

Pengalaman

Postpartum

Rupture Perineum

Kualitatif

\begin{abstract}
ABSTRAK
Abstrak: Rupture perineum berdampak pada bio/fisik, psikologis, seksual dan sosial serta kualitas hidup pada ibu postpartum. Tujuan penelitian untuk mengetahui biopsikoseksual dan sosial ibu postpartum dengan riwayat rupture perineum. Metode penelitian adalah scoping review menggunakan mesin pencarian pada database PubMed, Proquest, Wiley Online Library dan Science Direct pada Januari 2008 sampai Desember 2018. Berdasarkan hasil scoping review ditemukan tema : "dampak rupture perineum pada ibu postpartum", "upaya pencegahan rupture perineum" dan "pelayanan masa nifas". Review jurnal yang ditemukan seluruhnya berasal dari Negara Maju.

Abstract: Perineal laceration has an impact on bio / physical, psychological, sexual and social as well as quality of life in postpartum mothers. The aim of the study was to determine the biopsychosexual and social aspects of postpartum mothers with a history of perineal laceration. The research method used search engines in the PubMed, Proquest, Wiley Online Library and Science Direct databases from January 2008 to December 2018. Based on the review results of the article found themes: "impact of perineal laceration on postpartum mothers", "efforts to prevent perineal laceration" and "postpartum childbirth service". The review articles found were entirely from Developed Countries.
\end{abstract}

\section{A. LATAR BELAKANG}

Berdasarkan hasil literatur, sekitar $85 \%$ wanita yang melakukan persalinan pervaginam akan mengalami rupture perineum, dan sekitar 60-70\% rupture tersebut membutuhkan jahitan pada perineum. Rupture perineum dapat meningkatkan angka kesakitan, baik dalam jangka waktu pendek ataupun jangka waktu yang lama. Risiko ataupun komplikasi yang ditimbulkan tergantung dari derajat rupture. Meskipun telah dilakukan tatalaksana dengan baik, rupture perineum dapat meningkatkan komplikasi pada masa postpartum [2].

Rupture perineum dapat menyebabkan nyeri perineum atau ketidaknyamanan dalam beberapa hari pertama setelah persalinan sehingga sering membutuhkan obat pereda nyeri. Sebanyak 40\% perempuan melaporkan rasa sakit pada 2 minggu pertama setelah persalinan, sebanyak 20\% masih mengalami nyeri pada 8 minggu setelah persalinan, dan sebanyak $7 \%$ hingga $9 \%$ masih melaporkan nyeri pada 3 bulan setelah persalinan [2]. Komplikasi jangka panjang yang dapat terjadi antara lain infeksi, dyspareunia, inkontinensia urin, inkontinensia feses, fistula vesicovaginalis dan kerusakan spincter ani. Angka kejadian kerusakan spincter ani dilaporkan sebesar o.6$10.2 \%$ [4], [15].
Selain berdampak pada kondisi fisik ibu postpartum, rupture perineum juga berdampak pada kondisi psikologis ibu. Dampak psikologis dari rupture perineum adalah kecemasan akan kondisi jahitan perineum sehingga mempengaruhi mobilisasi dan aktifitas sehari-hari. Dampak lainnya adalah takut untuk buang air besar dan takut untuk memulai hubungan seksual karena khawatir akan timbulnya rasa nyeri dan khawatir jahitan akan terbuka kembali [23].

Dampak lain yang ditimbulkan oleh rupture perineum adalah permasalahan seksual. Sebanyak 91,3\% perempuan mengalami setidaknya satu masalah seksual pada periode postpartum [10]. Penelitian lain mengungkapkan sekitar $80 \%$ wanita melaporkan masalah seperti nyeri saat berhubungan intim, kurangnya lubrikasi pada vagina dan hilangnya libido dalam 3 bulan pertama postpartum. Perubahan psikososial juga memiliki dampak signifikan pada hubungan seksual [22].

Berbagai dampak fisik, psikologis, dan seksual yang dialami oleh ibu postpartum dengan riwayat rupture perineum dapat menyebabkan kecemasan dan meningkatkan risiko depresi postpartum. Kondisi ini dapat menyebabkan perempuan menarik diri dari lingkungan sosial, menurunkan keintiman hubungan suami istri bahkan menyebabkan penurunan kualitas hidup selama 10 tahun postpartum [6], [13]. 
Hal yang ditakutkan oleh perempuan selama proses persalinan selain rasa sakit karena kontraksi adalah rupture perineum dan tindakan penjahitan rupture perineum. Rupture perineum yang ditakutkan oleh perempuan tidak hanya rupture yang terjadi secara alami tetapi juga tindakan episiotomy. Pengalaman ini seringkali menjadi momen yang cukup traumatik bagi para perempuan. Akibatnya banyak perempuan yang merasa takut untuk melahirkan pervaginam karena rumor yang beredar di masyarakat tentang sakitnya saat dilakukan penjahitan perineum [5]. Potensi morbiditas yang terkait dengan persalinan pervaginam cukup memprihatinkan. Terdapat kemungkinan bahwa hal ini berkontribusi pada peningkatan permintaan untuk operasi sectio caesaria [2].

Strategi efektif untuk menciptakan pengalaman melahirkan yang positif adalah mendukung perempuan selama proses persalinan, meminimalkan intervensi persalinan dan mempersiapkan kehamilan dan persalinan. Untuk itu peran bidan sebagai mitra perempuan sangat dibutuhkan dalam upaya promotif dan preventif untuk mengembalikan konsep kenormalan bahwa persalinan adalah proses alamiah, minim intervensi dan minim traumatik [18].

\section{B. METODE PENELITIAN}

\section{Fokus Pertanyaan}

Fokus pertanyaan pada scoping review ini adalah "bagaimana biopsikoseksual dan sosial ibu postpartum dengan riwayat persalinan rupture perineum?”. Tujuan literature didefinisikan sebagai sintesis penelitian yang bertujuan untuk melakukan pencarian pelayanan asuhan masa nifas secara komprehensif dan mengidentifikasi konsep-konsep kunci, kesenjangan dalam penelitian, dan sebagai sumber bukti untuk menginformasikan praktik, kebijakan, dan penelitian tentang asuhan masa nifas secara komprehensif [14].

\section{Framework Population (P), Exposure (E), Outcome (O) dan Study Design (S)}

Framework Population, Exposure, Outcome dan Study Design (PEOS) merupakan pengembangan fokus pertanyaan dan strategi pencarian pada penelitian kualitatif. Penggunaan PEOS membantu untuk mengidentifikasi konsep-konsep kunci dalam fokus pertanyaan, mengembangkan istilah pencarian yang sesuai untuk menggambarkan masalah dan menentukan kriteria inklusi dan ekslusi. PEOS digunakan untuk mengidentifikasi unsur-unsur pertanyaan penelitian kualitatif [9]. Adapun identifikasi unsur-unsur pertanyaan penelitian menggunakan PEOS adalah sebagai berikut :
TABEL 1.

Identifikasi Unsur-Unsur Pertanyaan Penelitian Menggunakan PEOS

\begin{tabular}{lllc}
\hline $\begin{array}{c}\text { Population } \\
\text { and } \\
\text { problems }\end{array}$ & Exposure & $\begin{array}{l}\text { Outcomes } \\
\text { or themes }\end{array}$ & $\begin{array}{c}\text { Study } \\
\text { Design }\end{array}$ \\
\hline $\begin{array}{l}\text { Postpartum } \\
\text { Puerperium }\end{array}$ & Perineal & Views & Qualitative \\
After & Perineal & $\begin{array}{l}\text { Experience } \\
\text { Opinion }\end{array}$ & Study \\
Childbirth & Tears & Perspective & \\
& Perineal & & \\
& Trauma & & \\
& Perineum & & \\
& Intact & & \\
\hline
\end{tabular}

\section{Identifikasi Studi yang Relevan}

Pada scoping review ini peneliti melakukan identifikasi studi literature. Langkah pertama adalah pembuatan framework sebagai dasar untuk menentukan kriteria inklusi dan eksklusi supaya data yang dicari tidak melebar dan fokus pada konteks yang dicari. Kedua, menyusun keyword yang didesain dan difokuskan pada framework. Ketiga, memasukkan keyword tersebut ke dalam mesin pencarian pada database PubMed, ProQuest, Wiley Online Library dan Science Direct. Pada database PubMed, ProQuest, Wiley Online Library dan Science Direct juga mengatur filter yang ada di laman tersebut seperti filter Full Text, Data Publish in 10 years ago, Human, Female, dan filter Bahasa Inggris. Langkah keempat, setelah ditemukan jumlah artikel yaitu PubMed sebanyak 14 artikel, ProQuest sebanyak 42 artikel, Wiley Online Library sebanyak 201 artikel dan Science Direct sebanyak 156 artikel. Dari keempat laman tersebut kemudian di simpan ke dalam mesin bibliography Zotero. Di Zotero data sudah terinput dan data tersebut lalu di filter sesuai dengan framework. Artikel yang tidak sesuai dikeluarkan dari folder "relevan". Temuan jumlah artikel dan proses filter akan dibahas di Prisma Flowchart. Adapun keyword yang digunakan dalam pencarian mesin pencarian pada database PubMed, ProQuest, Wiley Online Library dan Science Direct adalah sebagai berikut : "women's experiences" AND "perineal laceration" OR "perineal tears" OR "perineum intact" OR "perineal trauma" AND qualitative.

\section{Prisma Flowchart}

Prisma Flowchart merupakan diagram pelaporan untuk tinjauan sistematis pada proses literature review untuk menjelaskan alur pencarian scoping review dan memperjelas transpalansi pencarian literature [12]. Adapun Prisma Flowchart dalam penelitian ini adalah sebagai berikut : 


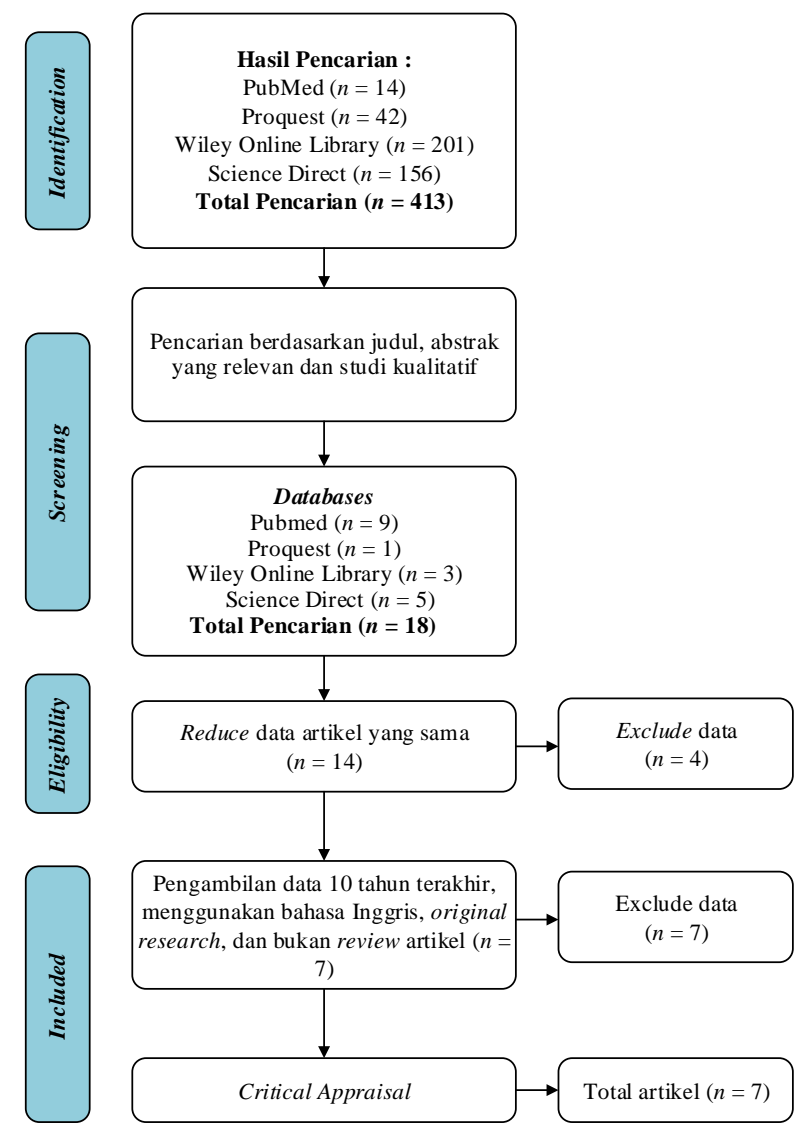

Gambar 1. Prisma Flowchart Biopsikoseksual dan Sosial Ibu Postpartum dengan Riwayat Persalinan Rupture Perineum

\section{Ekstraksi Data}

TABEL 2.

Ekstraksi Data Bio Psiko Seksual dan Sosial Ibu Postpartum dengan Riwayat Persalinan Rupture Perineum

\begin{tabular}{|c|c|c|c|c|c|c|}
\hline $\begin{array}{l}\mathbf{N} \\
\mathbf{o}\end{array}$ & $\begin{array}{c}\text { Judul/Penulis/ } \\
\text { Tahun/Negara }\end{array}$ & & $\begin{array}{c}\text { Metode } \\
\text { Penelitian }\end{array}$ & $\begin{array}{c}\text { Tujuan } \\
\text { Penelitian }\end{array}$ & Tema & Hasil Penelitian \\
\hline 1 & 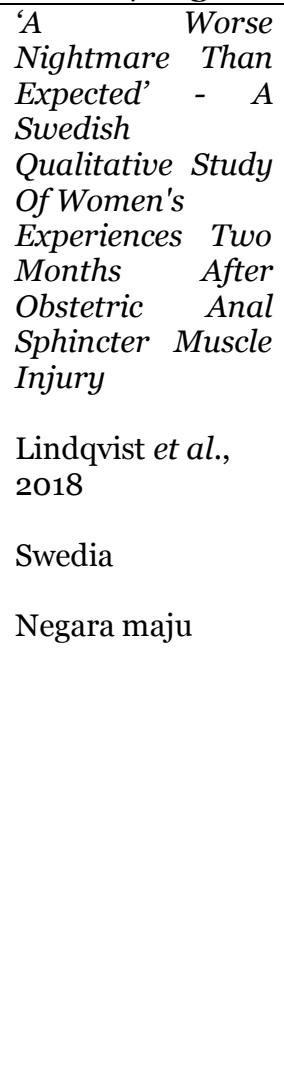 & a. & $\begin{array}{l}\text { Penelitian } \\
\text { kualitatif } \\
\text { dengan } \\
\text { pendekatan } \\
\text { induktif } \\
\text { Pengumpulan } \\
\text { data dengan } \\
\text { tanggapan } \\
\text { tertulis yang } \\
\text { singkat dan } \\
\text { komprehensif } \\
\text { pada 1248 } \\
\text { wanita yang } \\
\text { terdaftar di } \\
\text { register } \\
\text { nasional } \\
\text { pelaporan } \\
\text { rupture } \\
\text { perineum } \\
\text { Pengumpulan } \\
\text { data pada } 1 \\
\text { Januari 2014 } \\
\text { sampai } 31 \\
\text { Desember } \\
\text { 2016 } \\
\text { Analisis data } \\
\text { menggunakan } \\
\text { inductive } \\
\text { qualitative } \\
\text { content }\end{array}$ & $\begin{array}{l}\text { Mengeksplorasi } \\
\text { pengalaman } \\
\text { perempuan } \\
\text { pada } 2 \text { bulan } \\
\text { pertama setelah } \\
\text { cedera sfingter } \\
\text { ani obstetrik } \\
\text { (OASIS) saat } \\
\text { persalinan }\end{array}$ & $\begin{array}{l}\text { Terdapat } 1 \text { tema, } 3 \text { kategori } \\
\text { dan } 9 \text { subkategori yang } \\
\text { diidentifikasi, yaitu : } \\
\text { a. Tema : Mimpi buruk } \\
\text { yang lebih buruk dari } \\
\text { yang diharapkan } \\
\text { b. Kategori : } \\
\text { 1) Menghadapi } \\
\text { keterbatasan fisik dan } \\
\text { psikologi sehari-hari } \\
\text { 2) Hidup dengan } \\
\text { harapan yang hancur } \\
\text { 3) Menavigasi dalam } \\
\text { perawatan kesehatan } \\
\text { c. Subkategori : } \\
\text { 1) Menderita rasa nyeri } \\
\text { yang menetap } \\
\text { 2) Menderita } \\
\text { inkontinensia } \\
\text { 3) Menderita tekanan } \\
\text { mental } \\
\text { 4) Perasaan terisolasi } \\
\text { 5) Merasakan komplikasi } \\
\text { fisik lainnya } \\
\text { 6) Perasaan tidak cukup } \\
\text { baik } \\
\text { 7) Tergantung dukungan } \\
\text { 8)Perasaan acuh tak } \\
\text { acuh } \\
\text { 9) Tidak dianggap serius }\end{array}$ & $\begin{array}{llr}\text { a. } & \text { Riwayat OASIS saat } \\
\text { persalinan memberikan } \\
\text { pengalaman yang buruk } \\
\text { bagi kehidupan perempuan } \\
\text { secara fisik maupun } \\
\text { psikologis sehingga } \\
\text { mempengaruhi hubungan } \\
\text { dengan pasangan dan bayi. } \\
\text { b. Perempuan dengan OASIS } \\
\text { berusaha mencari } \\
\text { pemecahan masalah kepada } \\
\text { tenaga kesehatan. Akan } \\
\text { tetapi kenyataannya tidak } \\
\text { sesuai dengan yang } \\
\text { diharapkan. } \\
\text { c. Perempuan dengan OASIS } \\
\text { merasa sulit untuk } \\
\text { mengungkapkan sedangkan } \\
\text { keluhannya sang } \\
\text { tenaga kesehatan kurang } \\
\text { peka terhadap apa yang } \\
\text { dikeluhkan oleh perempuan } \\
\text { d. Perempuan kurang } \\
\text { mendapatkan informasi } \\
\text { tentang perawatan } \\
\text { perineum a }\end{array}$ \\
\hline
\end{tabular}




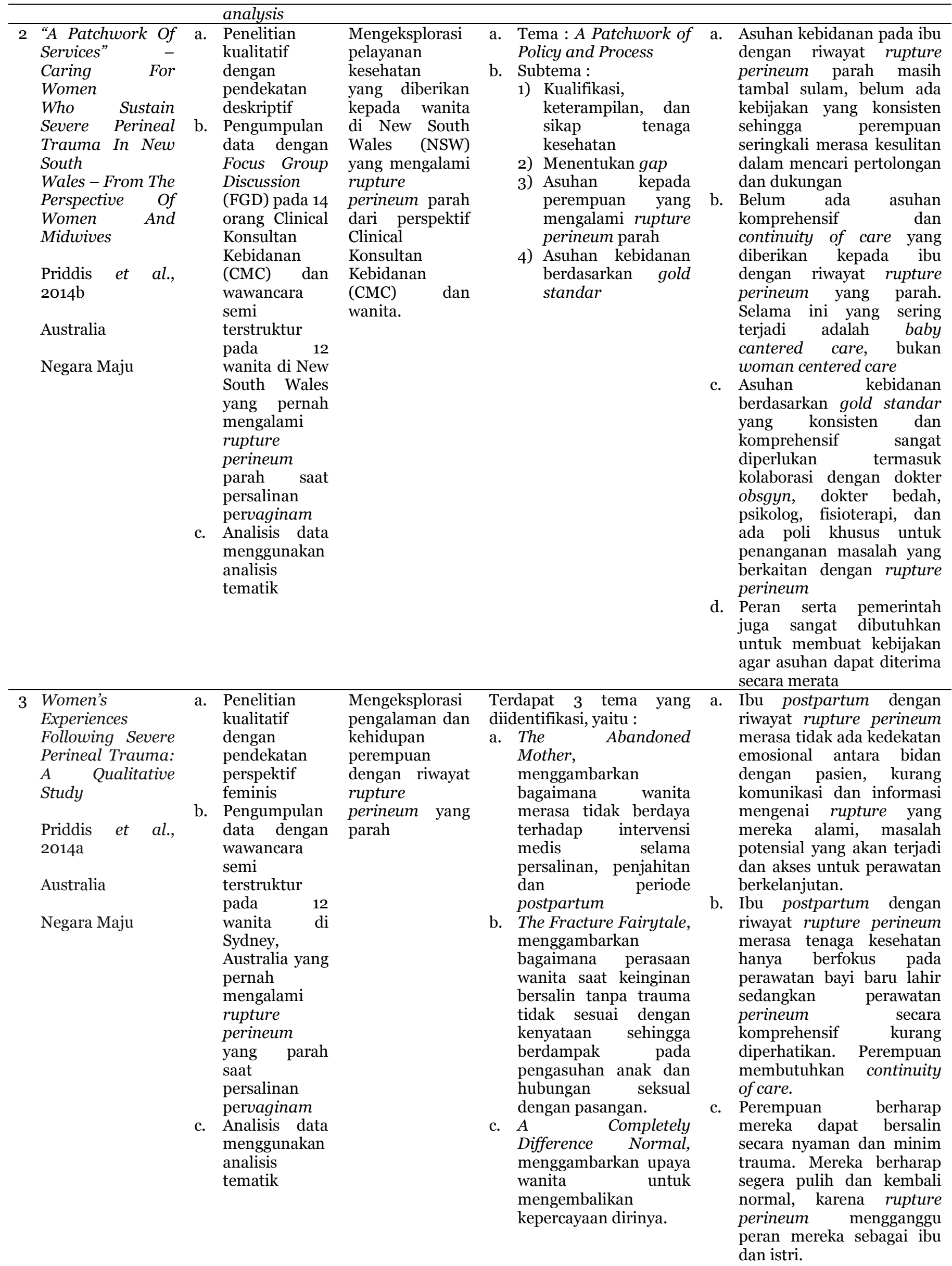




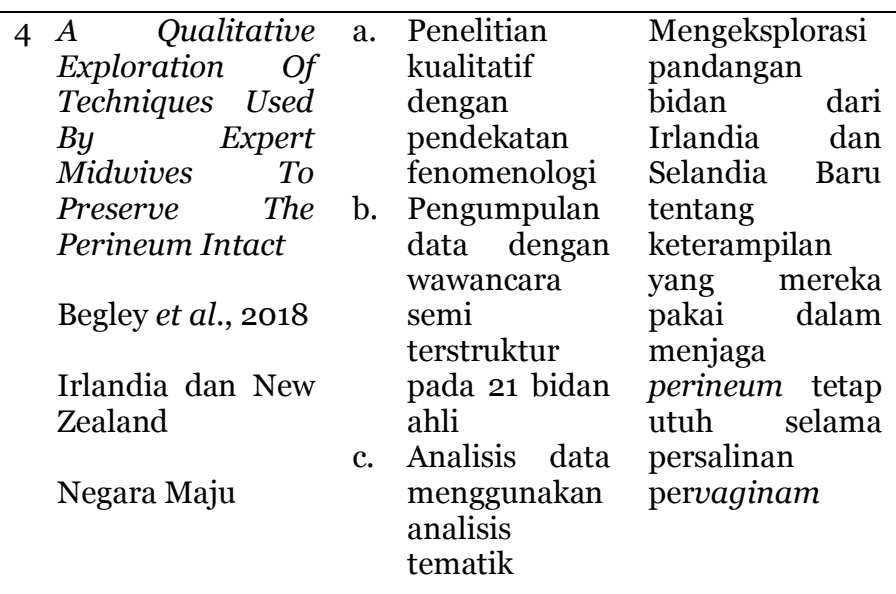

Terdapat 4 tema utama yang diidentifikasi, yaitu :

a. Tenang dan dapat mengontrol persalinan, dengan subtema : mengamati dengan tenang, mengembangkan

hubungan saling percaya, mendukung wanita untuk memegang kendali

b. Posisi dan teknik persalinan kala II, dengan sub tema : posisi persalinan, pengamatan perineum dan teknik menolong persalinan

c. Penahanan perineum, dengan sub tema : posisi tangan, menahan kepala agar tidak terlalu defleksi, menahan perineum

d. Sangga susur, dengan sub tema : sangga kepala dan bahu, lahirkan badan bayi
Tenang dan dapat mengontrol persalinan

1) Memberdayakan perempuan dan menciptakan hubungan saling percaya

2) Memastikan lingkungan yang tenang dan nyaman

3) Mempersiapkan, meyakinkan dan mendukung wanita untuk terhubung hanya dengan suara bidan pada saat persalinan

4) Komunikasi aktif dengan wanita dan mendukungnya untuk memegang kendali saat persalinan

b. Posisi dan teknik persalinan kala II
1) Posisi persalinan senyaman pasien maupun upright position

2) Menggunakan kompres hangat pada perineum

3) Mempertimbangkan gel atau minyak untuk pelumasan jika perlu

4) Mempertimbangkan untuk menggunakan anestesi lokal sebagai upaya terakhir sebelum merencanakan episiotomy

c. Penahanan perineum

1) Jika wanita dalam kendali maka bidan akan mudah mengendalikan kepala janin

2) Tekanan lembut di kepala untuk mengendalikan kekuatan ekspulsif

3) Tahan perineum menggunakan jari dan ibu jari, telapak tangan memegang anus

4) Longgarkan perineum jika perlu

d. Sangga susur

1) Memastikan janin lahir secara gentle birth dan ibu menguasai nafas

2) Memberikan waktu perineum untuk meregang sambil memantau detak jantung janin

3) Tunggu janin melakukan putar paksi 


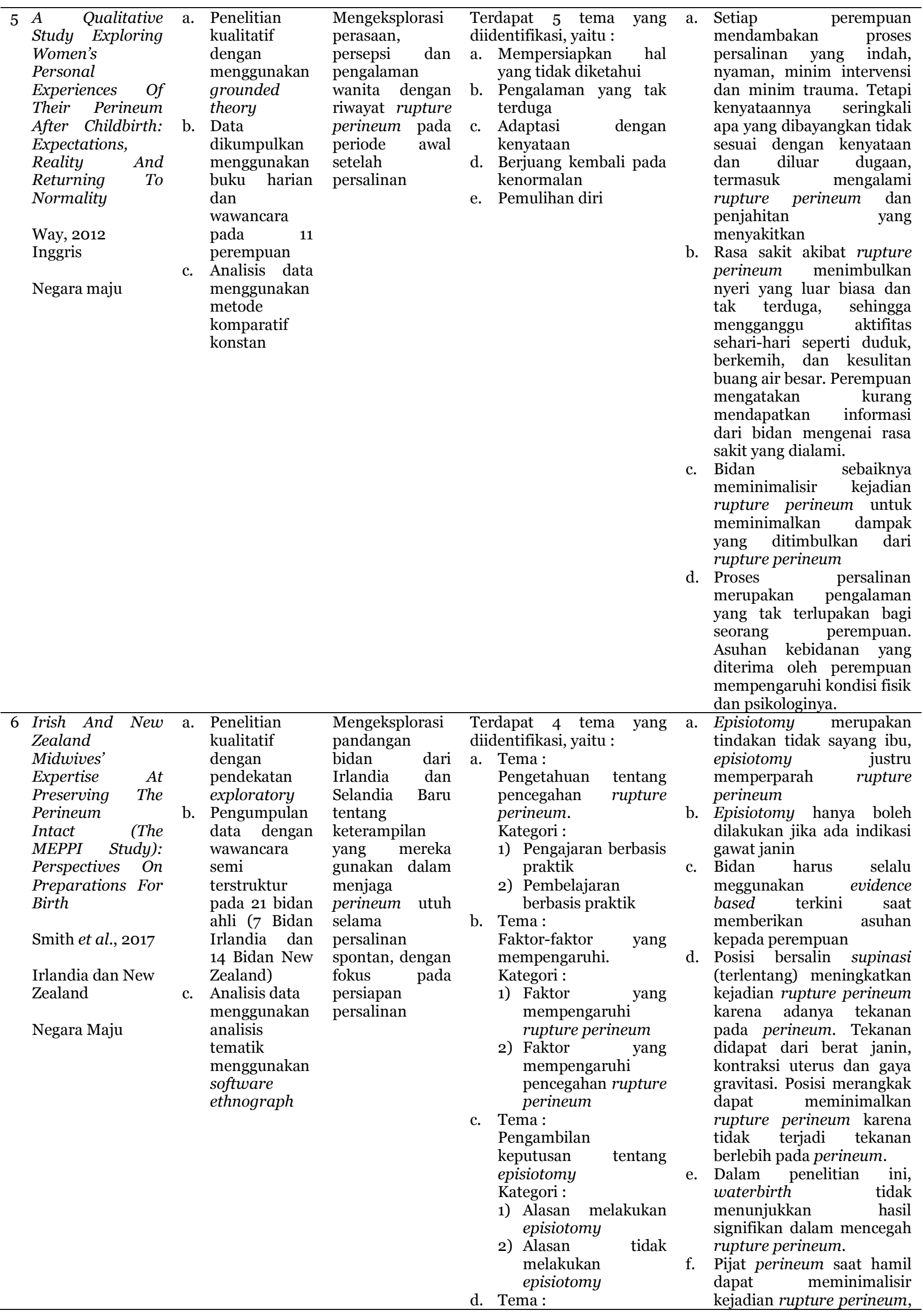




$\begin{aligned} & \text { Persiapan } \\ & \text { pencegahan } \\ & \text { perineum }\end{aligned}$
Kategoriam
1) Persiapan
kehamilan sejak
2) Penatalaksanaan
pencegahan rupture
perineum

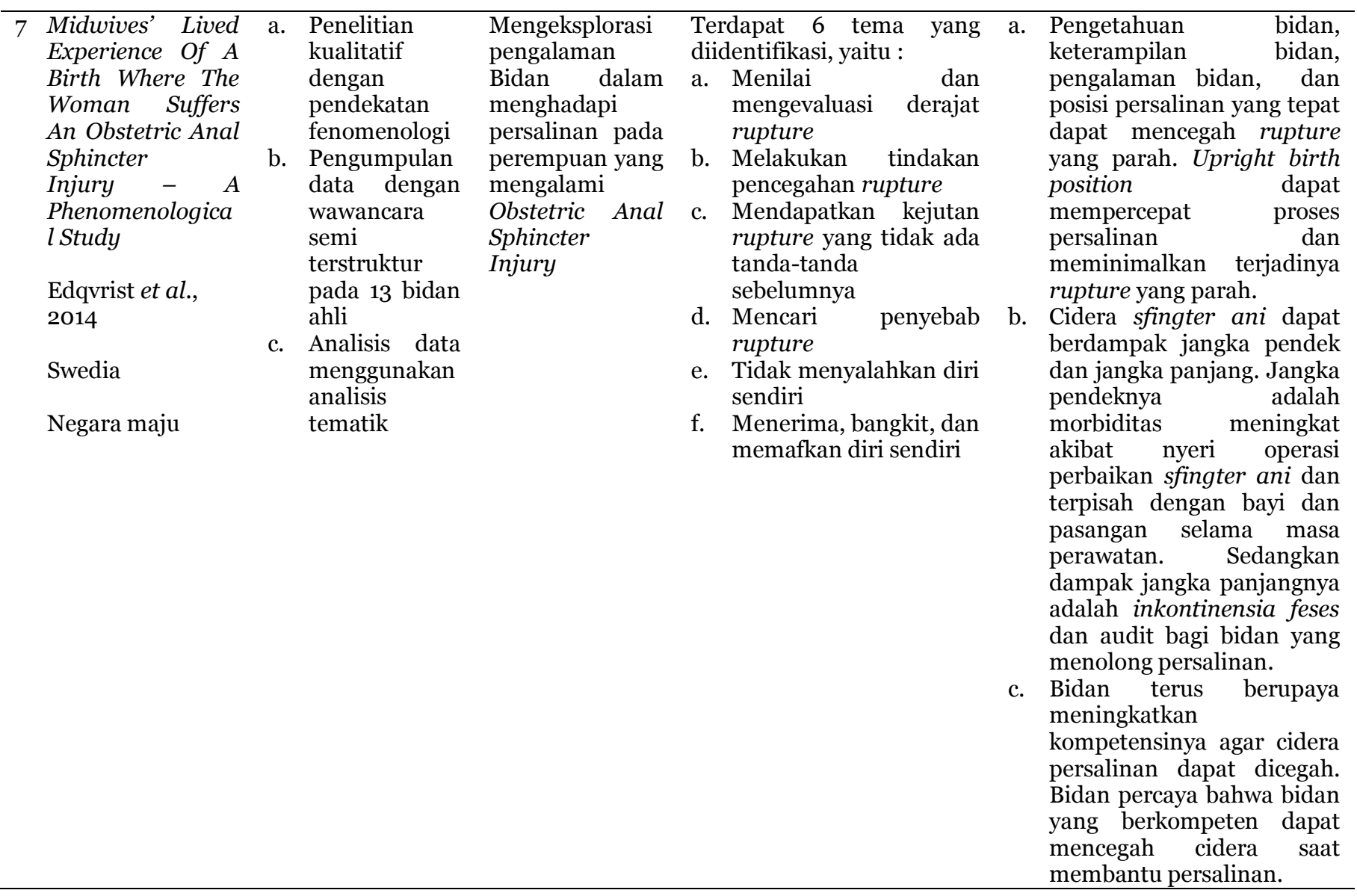




\section{Mapping / Scoping Literatur}

Berdasarkan jurnal yang didapat, sejumlah 7 jurnal yang terpilih menggunakan metode penelitian kualitatif. Semua jurnal yang didapat dari negara maju yaitu Australia, Inggris, Irlandia, New Zealand dan Swedia. Hasil scoping review ditemukan beberapa tema yang relevan dengan fokus review sebagai berikut:

TABEL 3.

Mapping Literature

\begin{tabular}{|c|c|c|}
\hline No & Tema & Sub Tema \\
\hline 1 & $\begin{array}{l}\text { Dampak Rupture } \\
\text { Perineum Pada Ibu } \\
\text { Postpartum }\end{array}$ & $\begin{array}{l}\text { a. Dampak fisik }{ }^{1,5,6,7} \\
\text { b. Dampak } \\
\text { psikologi1,2,3,4,5,7 } \\
\text { c. } \text { Dampak seksual1,3 }^{1,3} \text { Dampak sosial }{ }^{1,3} \\
\text { d. }\end{array}$ \\
\hline 2 & $\begin{array}{l}\text { Upaya Pencegahan } \\
\text { Rupture Perineum }\end{array}$ & $\begin{array}{l}\text { a. Upaya yang dilakukan } \\
\text { oleh perempuan } 4,6 \\
\text { b. Upaya yang dilakukan } \\
\text { oleh bidan } 4,5,6,7\end{array}$ \\
\hline 3 & Pelayanan Masa Nifas & 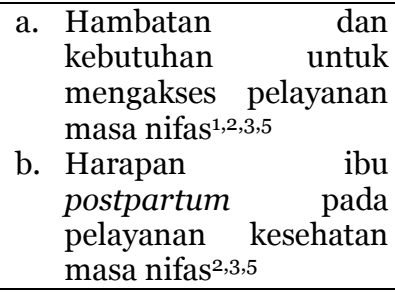 \\
\hline
\end{tabular}

\section{HASIL DAN PEMBAHASAN}

\section{Hasil Scoping Review}

\section{a. Dampak Rupture Perineum}

Rupture perineum dapat menyebabkan nyeri, inkontinensia urin, inkontinensia feses, masalah pencernaan karena ibu cenderung takut untuk buang air besar, prolaps dinding vagina, disfungsi seksual, kecemasan dan depresi postpartum. Kondisi ini dapat menyebabkan perempuan menarik diri dari lingkungan, menurunkan keintiman hubungan suami istri bahkan menyebabkan penurunan kualitas hidup selama 10 tahun postpartum [13]. Rupture perineum juga dapat menyebabkan dyspareunia, inkontinensia urin, inkontinensia flatus, inkontinensia feses dan berisiko meningkatkan angka kesakitan meliputi prolapse organ panggul dan fistula vesikovaginalis. Dampak fisik yang terjadi dapat mempengaruhi psikologis, sehingga berdampak pula pada kondisi sosial ibu postpartum. Ibu postpartum dapat mengalami isolasi dan peminggiran di lingkungan sosial akibat kesakitan yang berkelanjutan [15].

Hasil review jurnal lainnya menyebutkan bahwa rupture perineum berdampak pada dyspareunia, inkontinensia urin dan meningkatkan rasa nyeri [3]. Review jurnal lainnya juga menyebutkan bahwa rupture perineum berdampak pada peningkatan rasa nyeri, waktu penyembuhan luka yang lama, meningkatkan infeksi, inkontinensia urin, dyspareunia, dan memperpanjang waktu untuk memulai hubungan seksual dengan pasangan setelah melahirkan sampai dengan 3 bulan postpartum [20].

Hasil temuan ini juga didukung oleh review jurnal lainnya yang menyebutkan bahwa rupture perineum berdampak pada peningkatan rasa nyeri, dyspareunia dan meningkatkan risiko depresi postpartum [17]. Review jurnal lainnya juga menyebutkan bahwa rupture perineum dapat meningkatkan nyeri, dyspareunia, inkontinensia feses, dan memperpanjang waktu untuk memulai hubungan seksual dengan pasangan setelah melahirkan. Kondisi ini berdampak pada kehidupan sehari-hari dan menurunkan kualitas hidup perempuan [7].

Upaya Pencegahan Rupture Perineum

Upaya pencegahan rupture perineum yang dilakukan antara lain mempersiapkan sejak masa hamil, meliputi pijat perineum agar tidak terjadi rupture perineum baik rupture spontan ataupun rupture yang disengaja (episiotomy). Episiotomy hanya dilakukan bila ada indikasi gawat janin. Sedangkan pencegahan rupture perineum yang dilakukan menjelang persalinan antara lain posisi dan teknik persalinan kala II meliputi : posisi bersalin upright position untuk mengurangi tekanan dan gravitasi pada perineum, menggunakan kompres hangat pada perineum, mempertimbangkan penggunaan gel atau minyak untuk pelumasan jika perlu, mempertimbangkan untuk menggunakan anestesi lokal sebagai upaya terakhir sebelum merencanakan episiotomy, menunggu janin melakukan putar paksi dan memastikan janin lahir secara gentle birth dan ibu menguasai nafas. Selain itu bidan dapat memberdayakan perempuan dan menciptakan hubungan saling percaya, memastikan lingkungan yang tenang dan nyaman, meyakinkan dan mendukung wanita untuk terhubung hanya dengan suara bidan pada saat persalinan, komunikasi aktif dengan wanita serta mendukungnya untuk memegang kendali saat persalinan [3].

Hasil review jurnal lainnya juga menyebutkan bahwa episiotomy merupakan tindakan tidak sayang ibu, episiotomy justru memperparah rupture perineum dan hanya boleh dilakukan jika ada indikasi gawat janin. Posisi bersalin supinasi (terlentang) meningkatkan kejadian rupture perineum karena adanya tekanan pada perineum. Tekanan didapat dari berat janin, kontraksi uterus dan gaya gravitasi. Posisi merangkak dapat meminimalkan rupture perineum karena tidak terjadi tekanan berlebih pada perineum. Pijat perineum saat hamil dapat meminimalisir kejadian rupture perineum, tetapi terdapat ketentuan khusus dalam melakukan pijat perineum [17].

Hal ini juga didukung oleh review jurnal lainnya yang menyebutkan bahwa pengetahuan bidan, keterampilan bidan, pengalaman bidan, dan posisi persalinan yang tepat dapat mencegah rupture yang parah. Upright birth position dapat mempercepat proses persalinan dan meminimalkan terjadinya rupture yang parah. Bidan harus terus berupaya meningkatkan kompetensinya agar cidera persalinan dapat dicegah karena bidan yang berkompeten dapat mencegah cidera saat membantu persalinan [7].

\section{b. Pelayanan Masa Nifas}

Ibu postpartum dengan riwayat rupture perineum berusaha mencari pemecahan masalah kepada tenaga kesehatan, akan tetapi kenyataannya 
tidak sesuai dengan yang diharapkan. Ibu postpartum dengan riwayat rupture perineum merasa sulit untuk mengungkapkan keluhannya sedangkan tenaga kesehatan kurang peka terhadap hal yang dikeluhkan oleh perempuan sehingga perempuan kurang mendapatkan informasi tentang perawatan perineum [13].

Ibu postpartum dengan riwayat rupture perineum merasa tidak ada kedekatan emosional antara bidan dengan pasien, kurang komunikasi dan informasi mengenai rupture yang mereka alami, masalah potensial yang akan terjadi dan akses untuk perawatan berkelanjutan. Ibu postpartum dengan riwayat rupture perineum merasa tenaga kesehatan hanya berfokus pada perawatan bayi baru lahir sedangkan perawatan perineum secara komprehensif kurang diperhatikan. Mereka berharap segera pulih dan kembali normal, karena rupture perineum mengganggu peran mereka sebagai ibu dan istri [15].

Asuhan kebidanan pada ibu dengan riwayat rupture perineum masih tambal sulam, belum ada kebijakan yang konsisten sehingga perempuan seringkali merasa kesulitan dalam mencari pertolongan dan dukungan. Asuhan kebidanan berdasarkan gold standar yang konsisten dan komprehensif sangat diperlukan termasuk kolaborasi dengan dokter obsgyn, dokter bedah, psikolog, fisioterapi, dan ada poli khusus untuk penanganan masalah yang berkaitan dengan rupture perineum. Peran serta pemerintah sangat dibutuhkan untuk membuat kebijakan agar asuhan dapat diterima secara merata [16].

Hal yang sama juga didapatkan dari review jurnal lainnya. Hasil review jurnal mengungkapkan bahwa perempuan mendambakan proses persalinan yang indah, nyaman, minim intervensi dan minim trauma. Tetapi kenyataannya seringkali hal yang dibayangkan tidak sesuai dengan kenyataan dan diluar dugaan, termasuk mengalami rupture perineum dan penjahitan yang menyakitkan. Rasa sakit akibat rupture perineum menimbulkan nyeri yang luar biasa dan tak terduga, sehingga mengganggu aktifitas sehari-hari seperti duduk, berkemih, dan kesulitan buang air besar. Selain itu perempuan juga mengatakan kurang mendapatkan informasi dari bidan mengenai rasa sakit yang dialami. Oleh karena itu, bidan sebaiknya meminimalisir kejadian rupture perineum untuk meminimalkan dampak yang ditimbulkan dari rupture perineum [20].

\section{Pembahasan}

\section{a. Dampak Rupture Perineum}

Rupture perineum dapat meningkatkan rasa nyeri, meningkatkan risiko infeksi, memperpanjang waktu penyembuhan luka, inkontinensia urin, inkontinensia flatus, inkontinensia feses, masalah pencernaan karena ibu cenderung takut untuk buang air besar, berisiko meningkatkan angka kesakitan meliputi prolapse organ panggul, prolaps dinding vagina dan fistula vesikovaginalis, dyspareunia, disfungsi seksual, meningkatkan kecemasan, meningkatkan risiko depresi postpartum dan memperpanjang waktu untuk memulai hubungan seksual dengan pasangan setelah melahirkan sampai dengan 3 bulan postpartum. Dampak fisik yang terjadi dapat mempengaruhi psikologis, sehingga berdampak pula pada kondisi sosial ibu postpartum. Ibu postpartum dapat mengalami isolasi, menarik diri dari lingkungan, dan peminggiran di lingkungan sosial akibat kesakitan yang berkelanjutan. Kondisi ini juga dapat menurunkan keintiman hubungan suami istri bahkan menyebabkan penurunan kualitas hidup selama 10 tahun postpartum [3], [7], [13], [15], [17], [20].

Rupture perineum dapat berdampak pada biopsikoseksual dan sosial ibu postpartum juga sejalan dengan penelitian lain yang menyebutkan bahwa rupture perineum berdampak pada nyeri perineum yang dirasakan saat periode postpartum. Ketidaknyamanan dan nyeri dirasakan sampai 2 minggu postpartum pada $30 \%$ perempuan dan $7 \%$ perempuan sampai 3 bulan postpartum. Nyeri perineum membutuhkan perawatan yang intens dan obat pereda nyeri. Rupture perineum juga berdampak dyspareunia, inkontinensia urin, inkontinensia feses maupun OASIS (Obstetric Anal Sphincter Injuries) sehingga menyebabkan permasalahan fisik, psikologis dan sosial. Kondisi ini mempengaruhi kemampuan perempuan dalam merawat bayi, aktifitas sehari-hari ataupun hubungan seksual suami istri sehingga mempengaruhi kualitas hidup perempuan [1].

Rupture perineum dipengaruhi oleh beberapa faktor. Faktor yang mempengaruhi rupture perineum antara lain kondisi demografi, nutrisi sebelum dan selama hamil, etnis Asia, riwayat keluarga dengan OASIS (Obstetric Anal Sphincter Injuries), nullipara, usia ibu di atas 30 tahun, berat janin, kala II lama dan malposisi janin dapat meningkatkan kejadian rupture perineum [1]. Etnis Asia memiliki perineum yang lebih pendek daripada etnis lain, sehingga semakin pendek perineum, maka kemungkinan terjadi rupture perineum akan semakin tinggi [21].

Sedangkan menurut literatur lainnya, faktor yang mempengaruhi rupture perineum adalah faktor demografi, nutrisi, etnis, kurangnya aktifitas fisik, paritas dan berat janin. Selain itu intervensi pada saat persalinan juga dapat mempengaruhi rupture perineum, antara lain posisi persalinan ataupun persalinan operatif pervaginam misalnya vacum ekstraksi [4].

\section{b. Upaya Pencegahan Rupture Perineum}

Upaya yang dapat dilakukan untuk mencegah rupture perineum adalah mempersiapkan sejak masa hamil, meliputi pijat perineum agar tidak terjadi rupture perineum baik rupture spontan ataupun rupture yang disengaja (episiotomy). Tindakan episiotomy merupakan tindakan tidak sayang ibu, episiotomy justru dapat memperparah rupture perineum dan hanya boleh dilakukan jika terdapat indikasi gawat janin. Sedangkan pencegahan rupture perineum yang dilakukan menjelang persalinan antara lain menggunakan kompres hangat pada perineum, mempertimbangkan penggunaan gel atau minyak untuk pelumasan jika perlu, mempertimbangkan untuk menggunakan anestesi lokal sebagai upaya 
terakhir sebelum merencanakan episiotomy, menunggu janin melakukan putar paksi dan memastikan janin lahir secara gentle birth dan ibu menguasai nafas. Selain itu posisi persalinan juga dapat mempengaruhi rupture perineum [3], [17].

Posisi bersalin supinasi (terlentang) dapat meningkatkan kejadian rupture perineum karena adanya tekanan pada perineum. Tekanan didapat dari berat janin, kontraksi uterus dan gaya gravitasi. Posisi terlentang dapat menekan pembuluh darah utama yang memasok oksigen dan nutrisi ke janin sehingga dapat mempengaruhi kesejahteraan janin. Posisi bersalin upright position dianjurkan untuk mengurangi tekanan dan gravitasi pada perineum. Upright birth position dapat mempercepat proses persalinan, memperluas diameter panggul, dan meminimalkan terjadinya rupture yang parah. Posisi merangkak juga dapat meminimalkan rupture perineum karena tidak terjadi tekanan berlebih pada perineum [8].

Selain itu, bidan dapat memberdayakan perempuan dengan menciptakan hubungan saling percaya, komunikasi aktif, memastikan lingkungan yang tenang dan nyaman, serta mendukung perempuan untuk memegang kendali saat persalinan. Selain itu pengetahuan, keterampilan, pengalaman, dan kompetensi bidan dalam membantu persalinan sangat diperlukan untuk mencegah rupture perineum. Karena bidan yang berkompeten dapat mencegah cidera saat membantu persalinan [3], [7].

Upaya pencegahan rupture perineum juga didukung oleh penelitian lain yang menjelaskan bahwa intervensi yang dapat dilakukan untuk mencegah rupture perineum antara lain pijat perineum, kompres hangat dan dingin dan teknik menejemen perineum. Selain itu, faktor penolong persalinan dengan teknik persalinan Flexion Technique dan Ritgen's Manoeuve juga dapat mencegah rupture perineum [1].

Pijat perineum juga sangat dianjurkan dilakukan sejak kehamilan 35 minggu. Pijat perineum dapat meningkatkan kelenturan otot-otot perineum sehingga mengurangi resistensi otot yang akan memungkinkan perineum meregang saat persalinan tanpa robek atau membutuhkan episiotomy. Keuntungan pijat perineum dapat menghemat biaya persalinan, meminimalkan jahitan perineum serta obat-obat analgesik (pereda nyeri) [2].

Upaya lain yang dapat dilakukan untuk mencegah rupture perineum adalah dengan senam/latihan penguatan otot dasar panggul. Latihan/senam otot dasar panggul direkomendasikan untuk memperkuat otot perineum sebelum dan sesudah persalinan. Berdasarkan hasil penelitian, latihan/senam otot dasar panggul yang dilakukan pada saat hamil dapat memperpendek waktu kala I dan kala II persalinan pada primipara, meminimalkan episiotomy, mencegah rupture perineum, dan meminimalkan penggunaan analgesic pada masa postpartum. Selain itu latihan/senam otot dasar panggul dapat membantu melindungi kerusakan otot dasar panggul pada saat persalinan, mencegah inkontinensia urin, inkontinensia feses, ataupun dyspareunia. Latihan/senam otot dasar panggul ini merupakan intervensi efektif yang direkomendasikan untuk semua wanita di usia 32 minggu kehamilan untuk mencegah rupture perineum [11].

\section{c. Pelayanan Masa Nifas}

Berdasarkan hasil temuan jurnal artikel menunjukkan bahwa ibu postpartum dengan riwayat rupture perineum kurang mendapatkan informasi tentang perawatan perineum. Ibu postpartum merasa sulit untuk mengungkapkan keluhannya sedangkan tenaga kesehatan kurang peka terhadap hal yang dikeluhkan oleh perempuan. Ibu postpartum dengan riwayat rupture perineum merasa tidak ada kedekatan emosional antara bidan dengan pasien, kurang komunikasi dan informasi mengenai rupture yang mereka alami, masalah potensial yang dapat terjadi dan akses untuk perawatan berkelanjutan. Ibu postpartum dengan riwayat rupture perineum merasa tenaga kesehatan hanya berfokus pada perawatan bayi baru lahir sedangkan perawatan perineum secara komprehensif kurang diperhatikan. Asuhan kebidanan pada ibu dengan riwayat rupture perineum masih tambal sulam, belum ada kebijakan yang konsisten sehingga perempuan seringkali merasa kesulitan dalam mencari pertolongan dan dukungan. Asuhan kebidanan berdasarkan gold standar yang konsisten dan komprehensif sangat diperlukan termasuk kolaborasi dengan dokter obsgyn, dokter bedah, psikolog, fisioterapi, dan ada poli khusus untuk penanganan masalah yang berkaitan dengan rupture perineum. Peran serta pemerintah sangat dibutuhkan untuk membuat kebijakan agar asuhan dapat diterima secara merata [13], [15], [16], [20].

\section{SIMPULAN DAN SARAN}

Berdasarkan hasil review jurnal menggunakan scoping review ditemukan tema :

1. Dampak rupture perineum pada ibu postpartum

2. Upaya pencegahan rupture perineum

3. Pelayanan masa nifas

Berdasarkan review jurnal yang ditemukan, tidak ditemukan hasil paper dari Negara Berkembang, sehingga review biopsikoseksual dan sosial pada ibu postpartum dengan riwayat rupture perineum merupakan gap masalah yang perlu untuk diteliti di Negara Berkembang, khususnya Indonesia.

\section{UCAPAN TERIMA KASIH}

Penulis mengucapkan terima kasih kepada pembimbing, sehingga penulis dapat menyelesaikan penyusunan scoping review ini.

\section{DAFTAR RUJUKAN}

[1] Aasheim,V., Abv, N., Lm, R., \& Lukasse, M. 2017. Perineal Techniques During The Second Stage Of Labour For Reducing Perineal Trauma (Review). Cochrane Database of Systematic Reviews. https://doi.org/10.1002/14651858.CDoo6672.pub3.ww w.cochranelibrary.com.

[2] Beckmann, MM., \& Stock, OM. 2013. Antenatal Perineal Massage For Reducing Perineal Trauma (Review). 
Cochrane Database of Systematic Reviews. https://doi.org/10.1002/14651858.CDoo5123.pub3.ww w.cochranelibrary.com.

[3] Begley, C., Guilliland, K., Dixon, L., Reilly, M., Keegan, C., Mccann, C., \& Smith, V. 2018. A Qualitative Exploration Of Techniques Used By Expert Midwives To Preserve The Perineum Intact. Women And Birth. https://doi.org/10.1016/J.Wombi.2018.04.015.

[4] Bulchandani, S., Watts, E., Sucharitha, A., \& Yates, D. 2015. Manual perineal support at the time of childbirth : a systematic review and meta-analysis. BJOG : An International Journal of Obstetrics and Gynaecology, https://doi.org/10.1111/1471-0528.13431

[5] Crookall, D. R., Fowler, G., Wood, C., \& Slade, P. 2018. A systematic mixed studies review of women's experiences of perineal trauma sustained during childbirth. Journal of Advanced Nursing. https://doi.org/10.1111/jan.13724.

[6] Dunn, A. B., Paul, S., Ware, L. Z., \& Corwin, E. J. 2015 Perineal Injury During Childbirth Increases Risk of Postpartum Depressive Symptoms and Inflammatory Markers. Journal of Midwifery and Women's Health. https://doi.org/10.1111/jmwh.12294.

[7] Edqvist, M., Lindgren, H., Lundgren, I., 2014. Midwives' lived experience of a birth where the woman suffers an obstetric anal sphincter injury--a phenomenological study. BMC Pregnancy Childbirth 14, 258. https://doi.org/10.1186/1471-2393-14-258.

[8] Gupta, J.K., Sood, A., Hofmeyr, G.J., Vogel, J.P., 2017. Position in the second stage of labour for women without epidural anaesthesia. Cochrane Database Syst. Rev. 5 , CDo02006.https://doi.org/10.1002/14651858.CDo020 06.pub4.

[9] Halas, G., Schultz, A.S.H., Rothney, J., Goertzen, L., Wener, P., Katz, A., 2015. A scoping review protocol to map the research foci trends in tobacco control over the last decade. BMJ Open 5, eoo6643. https://doi.org/10.1136/bmjopen-2014-006643.

[10] Karac, Z. 2011. Sexual problems in women during the first postpartum year and related conditions. Journal of Clinical Nursing, 21, 929-937. https://doi.org/10.1111/j.1365-2702.2011.03882.x.

[11] Leon-Larios, F., Corrales-Gutierrez, I., Casado-Mejía, R., Suarez-Serrano, C., 2017. Influence of a pelvic floor training programme to prevent perineal trauma: A quasi-randomised controlled trial. Midwifery 50, 72-77. https://doi.org/10.1016/j.midw.2017.03.015.

[12] Liberati, A., Altman, D.G., Tetzlaff, J., Mulrow, C., Gøtzsche, P.C., Ioannidis, J.P.A., Clarke, M., Devereaux, P.J., Kleijnen, J., Moher, D., 2009. The PRISMA statement for reporting systematic reviews and metaanalyses of studies that evaluate health care interventions: explanation and elaboration. J. Clin. Epidemiol. 62, e1-34 https://doi.org/10.1016/j.jclinepi.2009.06.006.

[13] Lindqvist, M., Persson, M., Nilsson, M., Uustal, E., \& Lindberg, I. 2018. 'A Worse Nightmare Than Expected'A Swedish Qualitative Study Of Women's Experiences Two Months After Obstetric Anal Sphincter Muscle Injury. https://doi.org/10.1016/J.Midw.2018.02.015.

[14] Pham, M.T., Rajić, A., Greig, J.D., Sargeant, J.M., Papadopoulos, A., McEwen, S.A., 2014. A scoping review of scoping reviews: advancing the approach and enhancing the consistency. Research Synthesis Methods 5, 371-385. https://doi.org/10.1002/jrsm.1123.

[15] Priddis, H., Schmied, V., \& Dahlen, H. 2014a. Women's Experiences Following Severe Perineal Trauma : A Qualitative Study. BMC Women's Health. doi : 10.1186/1472-6874-14-32.

[16] Priddis, H.S., Schmied, V., Kettle, C., Sneddon, A.,
Dahlen, H.G., 2014b. "A patchwork of services"--caring for women who sustain severe perineal trauma in New South Wales--from the perspective of women and midwives. BMC Pregnancy Childbirth 14, 236. https://doi.org/10.1186/1471-2393-14-236.

[17] Smith, V., Guilliland, K., Dixon, L., Reilly, M., Keegan, C., McCann, C., Begley, C., 2017. Irish and New Zealand Midwives' expertise at preserving the perineum intact (the MEPPI study): Perspectives on preparations for birth. Midwifery 55, 83-89. https://doi.org/10.1016/j.midw.2017.09.011.

[18] Taheri, M., Takian, A., Taghizadeh, Z., Jafari, N., Sarafraz, N., 2018. Creating a positive perception of childbirth experience: systematic review and metaanalysis of prenatal and intrapartum interventions. Reproductive Health $15, \quad 73$. https://doi.org/10.1186/s12978-018-0511-x.

[19] Wallwiener, S., Müller, M., Doster, A., Jeremias, R., Plewniok, K., Feller, S., Christian, M. 2017. Sexual activity and sexual dysfunction of women in the perinatal period : a longitudinal study. Archives of Gynecology and Obstetrics. https://doi.org/10.1007/s00404-017-4305-0.

[20] Way, S., 2012. A qualitative study exploring women's personal experiences of their perineum after childbirth: Expectations, reality and returning to normality. Midwifery 28, e712-e719. https://doi.org/10.1016/j.midw.2011.08.011.

[21] Wheeler, J., Davis, D., Fry, M., Brodie, P., \& Homer, C. S. E. 2012. Is Asian ethnicity an independent risk factor for severe perineal trauma in childbirth? A systematic review of the literature. Women and Birth, 25(3), 107113. https://doi.org/10.1016/j.wombi.2011.08.003.

[22] Woolhouse, H., Mcdonald, E., \& Brown, S. 2012. Women's experiences of sex and intimacy after childbirth : making the adjustment to motherhood. Journal of Psychosomatic Obstetrics \& Gynecology, 33(4), 185-190. https://doi.org/10.3109/0167482X.2012.720314

[23] Yolandia, R. 2015. Pengalaman Ibu Bersalin yang Mengalami Rupture Perineum Derajat 3-4 di RSUD Kabupaten Tangerang. Jurnal Ilmiah Kebidanan Indonesia Vol 8, No. 2, Juni 2018. ISSN : 2354-8169. doi: https://doi.org/10.33221/jiki.v8io2.149.

\section{PROFIL PENULIS UTAMA}

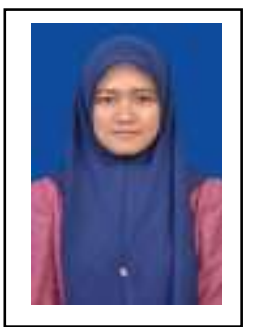

$\begin{array}{ll}\text { Nama lengkap } & : \text { Yolanda Montessori } \\ \text { TTL } & : \text { Sintang, 15 Januari } \\ 1990 & : 085743488070 \\ \text { No. HP } & : \text { Grogol VII RT 02, } \\ \text { Alamat } & \\ \text { Parangtritis, Kretek, Bantul, Daerah } \\ \text { Istimewa Yogyakarta }\end{array}$

Riwayat Pendidikan:

Sekolah Dasar Negeri 3 Mensiku, Binjai Hulu, Sintang, Kalimantan Barat 1996-2001

Madrasah Tsanawiyah Al-Zaytun Indramayu, Jawa Barat 2002-2004

Madrasah Aliyah Al-Zaytun Indramayu, Jawa Barat 20052008

Diploma III Kebidanan Akademi Kesehatan Karya Husada Yogyakarta 2010-2013

Diploma IV Bidan Pendidik Sekolah Tinggi Ilmu Kesehatan 'Aisyiyah Yogyakarta 2014-2015

Magister Kebidanan Universitas 'Aisyiyah Yogyakarta 2018 sekarang. 
82 Midwifery Journal | Vol. 5, No. 2, Juli 2020, hal 71-82

Penelitian :

Pengaruh Penyuluhan SADARI dengan Metode Demonstrasi Terhadap Keterampilan Melakukan SADARI Pada Siswi Kelas XI SMAN I Imogiri Bantul Tahun 2014

Systematic Literature Review Pengaruh Kontrasepsi Hormonal terhadap Disfungsi Seksual Pada Perempuan Tahun 2018 